\title{
Knowledge and Attitudes toward Advance Directives among Middle-Aged Women
}

\author{
Ji Won Choi, B.S.* and Yong Joo Rhee, Dr. P.H.** \\ "Department of Health Sciences, Dongduk Women's University, Seoul, Korea, ${ }^{\dagger}$ Department of Psychiatry and Behavioral \\ Sciences, Feinberg School of Medicine, Northwestern University, Chicago, IL, USA
}

Purpose: This study investigated knowledge of and attitudes toward advance directives (ADs) among middle-aged women in South Korea, their willingness to write ADs in the future, and the factors related to knowledge of and attitudes toward ADs. Methods: Data were collected using a self-administrated questionnaire completed by 154 middle-aged women aged 50 to 64 from February to March 2020. The questionnaire asked about participants' knowledge of and attitude toward ADs, willingness to write ADs in the future, experiences with life-sustaining treatment within their families, experience making decisions about life-sustaining treatment, and demographic characteristics. Results: Scores for both knowledge of and attitude toward ADs were relatively high. About $60 \%$ of participants gave wrong answers when asked if attorneys were required for writing $\mathrm{ADs}$. A higher knowledge score was significantly associated with a higher attitude score $(r=0.227, \mathrm{P}<0.01)$. The women were more likely to be willing to write ADs in the future when they reported a middle income level rather than a lower income level (odds ratio $[\mathrm{OR}]=5.952, \mathrm{P}<0.01$ ), considered themselves unhealthy $(\mathrm{OR}=5.873, \mathrm{P}<0.01)$, and graduated college or higher $(\mathrm{OR}=4.096, \mathrm{P}<0.05)$. Furthermore, women who thought that $\mathrm{ADs}$ would have an impact on treatment $(\mathrm{OR}=1.869, \mathrm{P}<0.05)$ and on their families $(\mathrm{OR}=1.447, \mathrm{P}<0.05)$ were more likely to be willing to write an $\mathrm{AD}$. Conclusion: This study shows that wrong information about ADs persists among middle-aged women, and significant factors associated with knowledge of and attitude toward ADs were identified. Targeted education programs about ADs need to be developed for middle-aged women.

Key Words: Middle aged women, Advance directives, Knowledge, Attitude
Received August 3, 2020

Revised March 2, 2021

Accepted March 18, 2021

\section{Correspondence to}

Yong Joo Rhee

ORCID:

https://orcid.org/0000-0002-9915-1188

E-mail:yrh759@dongduk.ac.kr

\section{INTRODUCTION}

\section{Background}

With the development of medical technology, it has become possible to extend the lives of patients with irreversible conditions using life support devices, which has resulted in an increasing number of patients prolonging life to a meaningless point despite considerable pain [1]. To put an end to a meaningless, painful life while still preserving a patient's dignity, the need to respect the patient's decision-making right has been raised [2]. To promote the dignity of end-of-life patients, the South Korean government enacted the According to the Act on Hospice and Palliative Care and Decisions on Life-Sustaining Treatment for Patients at the End of Life (hereinafter referred to as the Act on Decisions on Life-Sustaining Treatment), 
which has been implemented since February 2018 [3].

According to the Act on Decisions on Life-Sustaining Treatment, there are two ways to identify a person's wishes regarding life-sustaining treatment. The first is physician orders for life-sustaining treatment (POLST), which document the wishes of a terminally ill or dying patient to suspend or discontinue life-sustaining treatment. The second is advance directives (ADs), in which healthy adults aged 19 years or older record their wishes about life-sustaining treatment and hospice care ahead of death. Through ADs, individuals put plans and preferences in writing while they are healthy in the event that they become incapable of making decisions about treatment [4]. ADs play an important role in protecting the right to self-determination by clarifying patients' end-of-life wishes in advance and thus lessening the suffering of patients and their families [5].

Middle age is the period of life when an individual actively participates in the labor market and prepares for retirement immediately before entering the elderly stage. In particular, with most baby boomers, who previously belonged to the working-age population, reaching the age of 65 or older by 2020 [6], practical alternatives to deal with various issues related to caring for the increasing elderly population have been suggested and discussed. Among them, it is particularly important to address government policies relating to end-oflife care and the elderly. According to a study on the medical decision-making of end-of-life patients in South Korea, the opinions of doctors and family members have a significant influence on the medical decisions of end-of-life patients, with caregivers playing an especially important role in discussions about medical decisions $[7,8]$. According to a survey on the actual conditions of the elderly, the percentage of people receiving care from family members was $8.4 \%$, with most caregivers being a patient's spouse or daughter [9]. In addition, on average, caregivers of terminally ill patients were 51 years old or older and women [10,11].

Writing ADs, which has recently been officially supported by policy measures in South Korea, is the most important expression of a patient and family's decisions regarding the patient's end of life. To promote ADs, further knowledge is needed regarding people's knowledge of and attitudes toward ADs. According to the knowledge-attitude-practice model, acquired knowledge on health behaviors ultimately leads to changes in behavior due to changes in attitude [12]. In other words, positive and active attitudes toward certain topics are first expressed as intentions and then practiced, resulting in behavioral changes [13]. ADs are a representative end-of-life health care policy, and research on knowledge of and attitudes toward ADs among middle-aged women, who play a major role in caregiving, will provide the main basis for establishing and proceeding with policies regarding end-of-life health care services in the future.

South Korean academic journal papers and dissertations published since February 2018, when ADs officially entered into effect, include six on senior citizens, 13 on nurses, seven on nursing college students, four on adults 19 years or older, one on nursing college students and other college students, one on college students majoring in health care information management, one on breast cancer survivors, five on cancer patients, one on the families of cancer patients, one on hemodialysis patients, one on middle-aged people with acute myocardial infarction, and three on middle-aged adults. There is an insufficient number of studies on middle-aged women, who are primarily in charge of providing care in local communities and have a strong influence on end-of-life care. Therefore, this study investigated knowledge of and attitudes toward ADs among middle-aged women (daughters, daughters-in-law, relatives, and caregivers), who have a major influence on the changing demands of end-of-life care as baby boomers reach an elderly age and play a major role in providing care to $\mathrm{pa}^{-}$ tients in local communities, and also explored the factors affecting their willingness to write ADs.

\section{METHODS}

\section{Study participants}

Middle age is the period of life during which one prepares for old age after early adulthood. Middle-aged women, as caregivers, can have a great influence on the end-of-life medical decisions of their spouses and the elderly [7]. In previous studies, the average ages of female caregivers for terminally ill patients were 51 years or older [9] and 52.49 years [11]. Therefore, this study examined middle-aged women aged 50 to 64 
years who provided care for terminally ill patients.

Convenience sampling was used to identify middle-aged women who provided care in their communities. After obtaining permission, we conducted the study with middle-aged women aged 50 to 64 years old who patronized businesses and exercise centers in southern Gyeonggi Province and the Seoul area, understood the purpose of the study, and agreed to respond to a questionnaire. The study participants were limited to middle-aged women who engaged in independent daily activities within a community, resided in that community, and had no communication problems. A total of 174 participants were issued a self-reported questionnaire, and 154 responses were used for the final analysis after excluding incomplete questionnaires. The data collection period was from February 2020 to March 2020 and institutional review board approval was obtained from the researchers' institution (DDWU191002). Due to the COVID-19 pandemic, direct contact with participants was restricted, and we strictly observed the necessary quarantine regulations during the survey administration and data collection.

\section{Research tools}

\section{1) Knowledge of $A D s$}

Nine questions developed by Hong and Kim [14] on knowledge related to the $\mathrm{AD}$ document were asked. We obtained approval for the use of the tool from the developers through email. One point was issued for correct answers, and 0 points were issued for incorrect answers or if the respondent did not know an answer. Possible scores ranged from a minimum of 0 to a maximum of 9 , and a higher score indicated greater knowledge of ADs. In the study conducted by the developers of the tool, the reliability of the tool was shown by a Cronbach's alpha value of 0.85 , and in the current study, Cronbach's alpha was 0.72 .

\section{2) Attitude toward ADs}

In this study, we also used a tool that was developed, revised, and supplemented by Nolan and Bruder [15] in 2003 and was translated by Lee and Park [16]. We obtained approval to use the tool from the developers and translators. The tool consisted of a total of 16 questions, including four questions on opportunities to select treatment, eight questions on the effects of ADs on families, three questions on the effects of $\mathrm{ADs}$ on treatment, and one question on disease perceptions. A 4-point Likert scale (absolutely yes, yes, no, not at all) was used for assessment, with a higher score indicating a more positive attitude toward ADs. In the study conducted by the developers of the tool, a score of 40 or more was interpreted as showing a positive attitude [15], and Cronbach's alpha was 0.74. In the translators' study, Cronbach's alpha was 0.79, and in the current study, Cronbach's alpha was 0.74 .

\section{3) Experience with life-sustaining treatment and ADs}

Experience with life-sustaining treatment was assessed by asking two questions about the respondent's experiences with life-sustaining treatment in their family (parents, siblings, spouses, and children) and if they had made life-sustaining treatment decisions. "Have you written an AD?" and "Are you willing to write an $\mathrm{AD}$ ?" were asked to determine the respondent's experience with ADs. If a respondent had already completed an $\mathrm{AD}$ or was willing to write an $\mathrm{AD}$ in the future, she was considered to be willing to write an $\mathrm{AD}$.

\section{4) Sociodemographic characteristics}

The following eight sociodemographic characteristics were determined: education level (elementary school graduate, middle school graduate, high school graduate, college graduate or higher), religion (Protestant, Buddhist, Catholic, atheist, etc.), marital status (unmarried, married, divorced/separated, widowed, cohabitating with a partner), average monthly household income (less than 1 million won, 1 to 2 million won, 2 to 3 million won, 3 to 4 million won, 4 to 5 million won, 5 million won or over), if the participant had children, household type (cohabitated with: self + spouse, self + spouse+children, self + children, parents + self + spouse + children, parents + self, parents+self+spouse, or living alone), and subjective health status (very good, good, average, bad, very bad).

Sociodemographic characteristics were defined as follows for analysis in this study:

(1) The highest level of education was defined as high school graduate or below (elementary school graduates, middle school graduates, and high school graduates) or college graduate or above.

(2) Marital status was defined as cohabitation, which in- 
cluded people who were married or cohabitating with a partner, or non-cohabitation, which included people who were unmarried, divorced/separated, and widowed.

(3) Possible classifications for average monthly household income were below 3 million won (corresponding to the mean second quartile income of 2.94 million won), 3 million to 5 million won (corresponding to the mean third quartile income of 4.29 million won), and 5 million won or over, based on the household income and expenditure survey in the fourth quarter of 2019.

(4) Subjective health status was categorized, based on the research of Borg and Kristensen [17] and Borrell et al. [18], as healthy (people who answered "very good" and "good") and unhealthy (people who answered "moderate", "bad", and "very bad").

\section{Data analysis}

The data were analyzed using SPSS Statistics version 20.0 (IBM Corp., Armonk, NY, USA), and participants' sociodemographic characteristics, experiences of undergoing or $\mathrm{de}^{-}$ termining life-sustaining treatment in their family, experience with and willingness to writing an $\mathrm{AD}$, and knowledge of and attitudes toward ADs were calculated as frequency, percentage, mean, and standard deviation using descriptive statistics. Spearman correlation analysis was used to determine the relationship between participants' knowledge of and attitudes toward ADs, and logistic regression analysis was used to identify the factors that influenced participants' willingness to write an $\mathrm{AD}$.

\section{RESULTS}

\section{Sociodemographic characteristics and differences in knowledge of and attitudes toward ADs among middle-aged women}

A total of 154 middle-aged women participated in this study, and their sociodemographic characteristics are presented in Table 1 . The average age of the study participants was $54.01 \pm$ 3.8 years. The most common education level was high school graduate or below, with 97 participants (63\%), and the most common religion was Protestantism, with 59 participants
(38.3\%), followed by atheism (52 participants, 33.8\%). Cohabitation was the most frequently reported marital status (136 people, 88.3\%). The most common category of household income was less than 3 million won, with 68 participants (44.2\%), followed by 3 to 5 million won with 66 participants (42.9\%). Most participants (148 participants, 96.1\%) responded that they had children. For household type, 114 participants (74\%) answered "self+spouse+children". Slightly over half of the participants (80 participants, 51.9\%) reported a healthy subjective health status, while 74 participants (48.1\%) perceived their status as unhealthy.

Education level $(\mathrm{t}=-3.520, \mathrm{P}<0.01)$ and household type $(\mathrm{F}=2.36, \mathrm{P}<0.05)$ were significantly related to knowledge of ADs, while education level $(\mathrm{t}=-2.918, \mathrm{P}<0.01)$ and mean monthly household income $(\mathrm{F}=4.801, \mathrm{P}<0.05)$ were significantly related to attitudes toward ADs. The Scheffe post-hoc test for variables showing significant differences demonstrated that a mean monthly household income of less than 3 million won was associated with significantly more favorable attitudes toward ADs than an income of 5 million won or more.

\section{Middle-aged women's experiences with life- sustaining treatment and willingness to write ADs}

Table 2 shows the participants' experience related to lifesustaining treatment and willingness to write ADs. For the two questions on the experience of life-sustaining treatment in participants' families (parents, siblings, spouses, and children) and if they had made life-sustaining treatment decisions, 21 participants (13.6\%) answered "yes" for each question. Most participants had no experiences related to life-sustaining treatment.

While five participants (3.2\%) responded they had already filled out ADs, most of the participants had not written ADs, and most of the participants (149 participants, 69.8\%) reported they were willing to write ADs in the future.

\section{Knowledge of and attitudes toward ADs}

\section{1) Knowledge of $A D s$}

Table 3 shows the participants' knowledge of ADs and the correct answer rate for each question, with a higher score indicating more accurate knowledge of ADs. The average score for knowledge of ADs among the participants was $6.97 \pm 1.71$ 


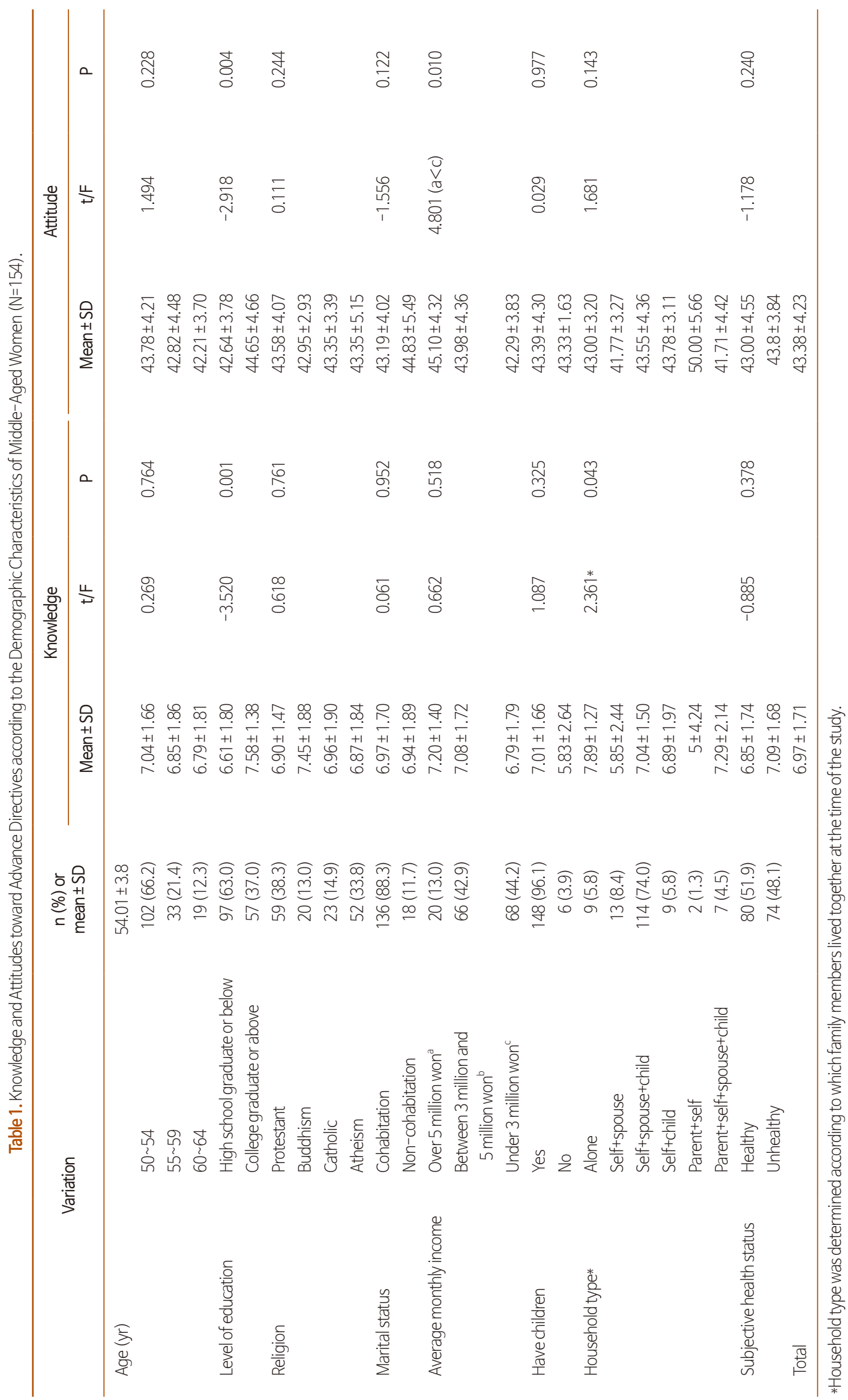


Table 2. Willingness to Write Advance Directives and Experiences of Life-Sustaining Treatment ( $N *=154)$.

\begin{tabular}{|c|c|c|c|c|}
\hline \multicolumn{3}{|c|}{ Options } & \multirow{2}{*}{$\frac{n}{21}$} & \multirow{2}{*}{$\begin{array}{c}\% \\
13.6\end{array}$} \\
\hline Life-sustaining treatment & Life-sustaining treatment for a family member & YES & & \\
\hline experiences & & No & 133 & 86.4 \\
\hline & Decision-making regarding life-sustaining treatment for a family member & Yes & 21 & 13.6 \\
\hline & & No & 133 & 86.4 \\
\hline & Advance directives have already been registered & Yes & 5 & 3.2 \\
\hline & & No & $149 *$ & 96.8 \\
\hline & Willingness to write advance directives in the future* & Yes & 104 & 69.8 \\
\hline & & No & 45 & 30.2 \\
\hline
\end{tabular}

*N=149 (5 missing).

Table 3. Middle-Aged Women's Knowledge of the Advance Directives.

\begin{tabular}{lc}
\hline \multicolumn{1}{c}{ Item } & $\begin{array}{c}\text { Correct } \\
\text { answer rate (\%) }\end{array}$ \\
\hline $\begin{array}{l}\text { A patient has a right to permit or reject the treatment } \\
\text { offered }\end{array}$ & 96.8 \\
A patient has a right to permit or reject LST & 96.8 \\
Advance directives are supposed to be prepared while & 87.7 \\
$\quad$ one is competent & 87.0 \\
A living will is an instruction with which one specifies & \\
$\quad$ what actions should be taken for their health if they & \\
are no longer able to make decisions due to illness or & \\
incapacity & 81.2 \\
A health care proxy is someone who is authorized to & \\
$\quad$ make care decisions for a person who designates & \\
him/her as their proxy & 72.7 \\
A living will cannot be changed or revoked once written & 72.1 \\
A health care proxy cannot be changed or revoked once & \\
$\quad$ designated & 64.3 \\
Any changes or revocation are possible whenever and & \\
$\quad$ wherever &
\end{tabular}

LST: life-sustaining treatment, AD: advance directives.

points. Specifically, the two items with the highest correct answer rate $(96.8 \%$ each) were "Patients have the right to allow or refuse treatment" and "Patients have the right to allow or refuse life-sustaining treatment", and the item that showed the lowest correct answer rate was "Patients must seek help from an attorney to write ADs", for which only $38.3 \%$ had correct knowledge.

\section{2) Attitudes toward ADs}

Table 4 shows the participants' attitudes toward ADs, with higher scores indicating more positive attitudes. The average score for participants' attitudes toward ADs was $43.38 \pm 4.23$
Table 4. Middle-Aged Women's Attitudes toward Advance Directives.

\begin{tabular}{|c|c|c|}
\hline \multicolumn{2}{|r|}{ Item } & \multirow{2}{*}{$\begin{array}{l}\text { Mean } \pm \text { SD } \\
2.73 \pm 0.57\end{array}$} \\
\hline Attitudes toward & 1. Opportunity for treatment choices & \\
\hline \multirow[t]{3}{*}{ advance directives } & $\begin{array}{l}\text { 2. Impact of advance directives on the } \\
\text { family }\end{array}$ & $2.71 \pm 0.26$ \\
\hline & $\begin{array}{l}\text { 3. Effect of an advance directive on } \\
\text { treatment }\end{array}$ & $2.95 \pm 0.41$ \\
\hline & 4. Illness perception & $3.06 \pm 0.53$ \\
\hline Total & & $43.38 \pm 4.23$ \\
\hline
\end{tabular}

points. Specifically, the most positive attitude toward ADs was found for perceptions of the disease related to health status (3.06 \pm 0.53 points), whereas a relatively negative attitude toward $\mathrm{ADs}$ was observed with regard to the impact of $\mathrm{ADs}$ on the family (decisions and burdens imposed on the family) (2.71 $\pm 0.26)$.

\section{Correlation between knowledge of and attitudes toward ADs among middle-aged women}

Spearman correlation analysis was performed to quantify the correlation between knowledge of and attitudes toward ADs among the participants. Knowledge of and attitudes toward ADs had a significant positive correlation $(r=0.227, \mathrm{P}<0.01)$.

\section{Factors affecting middle-aged women's willingness to write $A D s$}

In this study, to identify the factors that influenced the willingness of middle-aged women to write an $\mathrm{AD}$, we coded "no willingness to write an $\mathrm{AD}$ " as " 0 " and "willingness to write an $\mathrm{AD}$ " as "1" for logistic regression analysis, and the results are presented in Table 5 .

The goodness of fit of the logistic regression model of this 
Table 5. Factors Influencing Middle-Aged Women's Willingness to Write Advance Directives ( $N=154)$.

\begin{tabular}{lccc}
\hline \multicolumn{1}{c}{ Predictors } & OR & $95 \% \mathrm{Cl}$ & $\mathrm{P}$ \\
\hline Constant & 0.000 & - & - \\
Knowledge of advance directives & 1.261 & $0.925 \sim 0.171$ & 0.142 \\
Attitudes toward advance directives & & & \\
Opportunity to choose treatment & 0.828 & $0.682 \sim 1.005$ & 0.056 \\
Impact of advance directives on the family & 1.447 & $1.047 \sim 1.998$ & 0.025 \\
Effect of advance directives on treatment & 1.869 & $1.044 \sim 3.343$ & 0.035 \\
IIIness perception & 2.439 & $0.950 \sim 6.264$ & 0.064 \\
Family life-sustaining treatment experience (no) & 0.459 & $0.045 \sim 4.643$ & 0.510 \\
Family life-sustaining treatment decision experience (no) & 1.523 & $0.145 \sim 15.955$ & 0.725 \\
Level of education (collegegraduate or above) & 4.096 & $1.253 \sim 13.386$ & 0.020 \\
Religion & & & \\
D1 (Protestant) & - & - & 0.534 \\
D2 (Buddhism) & 1.583 & $0.335 \sim 7.482$ & 0.562 \\
D3 (Catholic) & 0.719 & $0.173 \sim 2.996$ & 0.651 \\
D4 (Atheism) & 1.959 & $0.558 \sim 6.872$ & 0.294 \\
Subjective health (unhealthy) & 5.873 & $1.875 \sim 18.395$ & 0.002 \\
Average monthly income & & & \\
D1 (over 5 million won) & - & - & 0.013 \\
D2 (between 3 millionand 5 million won) & 5.945 & $0.076 \sim 2.548$ & 0.004 \\
D3 (under 3 million won) & 2.614 & $0.050 \sim 0.562$ & 0.238 \\
Household type & & & \\
D1 (self+spouse) & - & - & 0.246 \\
D2 (self+spouse+child and parent+self+spouse+child) & 0.743 & $0.155 \sim 3.556$ & 0.710 \\
D3 (alone and parent+self) & 4.652 & $0.340 \sim 63.594$ & 0.249 \\
D4 (self+child) & 3.205 & $0.294 \sim 34.963$ & 0.339 \\
\hline
\end{tabular}

study was statistically significant: -2LL (Log-likelihood ratio $)=114.106\left(\chi^{2}=71.962, \mathrm{P}<0.001\right)$, Hosmer and Lemeshow $\chi^{2}=4.347$, and $\mathrm{P}<0.825$. The explanatory power of the independent variable for the regression model was approximately 53.2\% (Nagelkerke $\mathrm{R}^{2}=0.532$ ).

A more positive attitude toward the influence ADs has on the family corresponded to a 1.447 times higher likelihood of being willing to write $\mathrm{ADs}(\mathrm{P}<0.05,95 \% \mathrm{CI}: 1.047 \sim 1.998)$. A more positive attitude toward the Impact of ADs on treatment corresponded to a 1.869 times higher likelihood of being willing to write $\mathrm{ADs}$ ( $\mathrm{P}<0.05$, 95\% CI: 1.044 3.343). Participants who were college graduates or above were 4.096 times more likely to be willing to write $\mathrm{ADs}$ than those who were high school graduates or below ( $<<0.05,95 \%$ CI: 1.253 13.386). People whose subjective health status was unhealthy were 5.873 times more likely to be willing to write ADs than those who perceived themselves as healthy $(\mathrm{P}<0.01,95 \% \mathrm{CI}$ : 1.873 18.395). Participants with a mean monthly household income of 3 to 5 million won were approximately 5.952 times more likely to be willing to write ADs than those with an income of less than 3 million won $(\mathrm{P}<0.01,95 \%$ CI: 0.050 to 0.562).

\section{DISCUSSION}

This study was conducted to help with the development of policies related to ADs as one component of end-of-life policies by investigating knowledge of and attitudes toward ADs among middle-aged women, as well as factors influencing their willingness to write ADs. This is important since middleaged women are in a stage of life during which one prepares for old age and also have a major influence on patients' decision-making as primary caregivers,

The score for knowledge of ADs among middle-aged women was 6.97 points on average, which is similar to that of the general public and the elderly $[16,19]$ and lower than that of 
nurses in a previous study [20]. This difference is thought to be attributable to the specialized knowledge of nurses, who work in the medical field. In this study, the items with the highest correct answer rates were "Patients have the right to allow or refuse treatment" (96.8\%) and "Patients have the right to allow or refuse life-sustaining treatment" (96.8\%). The question with the lowest correct answer rate was "You must get the help of an attorney to write an $\mathrm{AD}$ " (38.3\%), which is consistent with previous studies involving the general public, the elderly, and nurses $[15,16,19,20]$. Based on the items with high correct answer rates, participants seemed to be very aware of patients' right of self-determination to decide their own treatment, whereas the question with a low correct answer rate indicates that participants were not very aware of the methods or institutions related to the writing of ADs or had not been provided sufficient information. During the course of the research, participants often had additional questions about the institutions related to the writing of ADs. We attribute this to the lack of publicity related to the consultation, writing, and registration of ADs supported by branch offices of the National Health Insurance Service across the nation. Given the purpose of ADs, which is to make a plan establishing the goals of and means for end-of-life treatment according to an individual's own wishes through the process of deciding and discussing preferences while they are still healthy [7], these results suggest that education on ADs tailored to middle-aged women should be provided. In particular, more detailed and accurate education and information transfer are necessary for middle-aged women who provide care in local communities. The results suggest that government-provided publicity programs and campaigns on ADs should be tailored to various places and subjects. In particular, it is necessary to strategically emphasize, promote, and repeat messaging on issues that may lead to misunderstandings.

In this study, the average score for attitudes toward ADs among middle-aged women was 43.38 points. According to the interpretation of the tool developers, Nolan and Bruder [15], 40 points or more indicate a positive attitude; therefore, the attitude of the participants toward ADs was positive in this study. In previous studies involving the general public, the elderly, and nurses [16,19-21], attitudes toward ADs were positive, with scores exceeding 40 points. This suggests that the overall population has a positive attitude toward ADs for ensuring the right to self-determination at the end of life, which includes the choice of death.

In this study, the factors that significantly influenced willingness to write an $\mathrm{AD}$ were education level, subjective health status, average monthly household income, the influence of writing an $\mathrm{AD}$ on treatment, and the influence of writing an $\mathrm{AD}$ on the family. Since the influence of ADs on treatment is the component of attitudes most associated with the right to self-determination, education on the purpose of writing an $\mathrm{AD}$ seems to be crucial. Responses regarding the impact of writing an $\mathrm{AD}$ on the family, which was examined using the items "ADs will serve to relieve the burden of care from my family" and "ADs will prevent my family from paying expensive medical expenditures”, may reflect an individual's thoughts on the impact of end-of-life care and caregiving on the family and thus also may be related to one's attitude toward death. In previous studies on death, elderly individuals considered a good death to mean dying at a similar time as their spouses without bothering their family members or others, and the general public considered a good death to mean being with close family members and friends without burdening other people [22,23]. South Korea is a country with a strong sense of family values, and people view family as the most basic social unit, paying primary attention to the interests of the family [24]. Therefore, further research is needed on family members of patients, their relationships, and their attitude toward ADs.

The number of single-person households consisting of people aged 65 years or older in South Korea is expected to increase from 1.203 million in 2015 to 3.719 million by 2045 [25]. According to the 2019 Population and Housing Census released by the National Statistical Office, $18.4 \%$ of the total number of single-person households consisted of people aged 70 years or older, $28 \%$ of whom were women [26]. In the midst of these changes in the demographic structure, it is necessary to guarantee one's own right to end-of-life determination rather than having the decision made by one's family. The current Act on Decisions on Life-Sustaining Treatment focuses on the judgment of the patient's family if a patient cannot express his or her opinions due to medical conditions. Consistent statements from two family members over the age of 19 years old (one statement if there is only one family member) are consid- 
ered the patient's wishes, and if this is not feasible, the decision is based on the agreement of all family members. However, if a family member cannot be located, is missing, or is unable to express his or her opinion, he or she is excluded from the scope of the family members whose opinion is factored into the decision [3]. However, given the increasing number of elderly people living alone, there may be no family members, and debate continues on how to make life-sustaining treatment decisions for patients whose family members cannot be identified. At the time when current middle-aged women reach old age, the proportion of the single-person households among the elderly population, especially among elderly women, is expected to increase, and it is necessary for them to be prepared for decisions related to end-of-life care. In the United States, Australia, and Taiwan, a legal representative is appointed during the process of writing an AD. In the United States, the law stipulates that a surrogate should be designated to make health care decisions in case of failure to appoint a representative, and in Australia, a support person is designated to help determine life-sustaining treatment according to the patient's values even before a surrogate is needed $[27,28]$. The matter of surrogates in association with life-sustaining treatment decisions merits continuing discussion, and in South Korean, an $\mathrm{AD}$ written when a patient is healthy is the expression of one's right to self-determination regarding lifesustaining treatment after a patient can no longer voice his or her opinions due to medical conditions. The support system for the right to self-determination, which has been recently established as a policy, includes a public guardian system for dementia patients who do not have families. For patients with dementia who are incapable of decision-making in the $a b^{-}$ sence of a direct surrogate or family member, the right to selfdetermination is protected through the public guardian system. Public guardians are paid from 200,000 won up to 400,000 won per month to support their activities, and they apply for social welfare services suitable for dementia patients, manage assets, and conduct regular monitoring [29]. As the scope of the ward for dementia patients is similar to that of the ward for those who require life-sustaining treatment, it is necessary to discuss end-of-life decisions that should be made for dementia patients, as well as the public guardian system.

As this is a cross-sectional study performed by collecting ac- cessible data through convenience sampling, the generalizability of the research results is limited. Due to the relatively small sample size, it was not possible to include all family structures, which limited the possibility of in-depth research in this regard.

In this study, which investigated middle-aged women's knowledge of and attitudes toward ADs, it was found that incorrect information was still widely believed with regard to major issues related to ADs. The primary factors influencing women's willingness to write ADs in the future were the right to self-determination and the effects of ADs on families. Therefore, it is necessary to provide customized promotional and educational programs on ADs targeting middle-aged women.

\section{CONFLICT OF INTEREST}

No potential conflict of interest relevant to this article was reported.

\section{ORCID}

Ji Won Choi, https://orcid.org/0000-0002-5827-7956

Yong Joo Rhee, https://orcid.org/0000-0002-9915-1188

\section{AUTHOR'S CONTRIBUTIONS}

Conception or design of the work: JWC, YJR. Data collection: JWC. Data analysis and interpretation: JWC, YJR. Drafting the article: JWC, YJR. Critical revision of the article: JWC, YJR. Final approval of the version to be published: JWC, YJR.

\section{SUPPLEMENTARY MATERIALS}

Supplementary materials can be found via https://doi. org/10.14475/jhpc.2021.24.2.74. 


\section{REFERENCES}

1. Lee MM, Yi MS. Experiences of families in the intensive care unit: Interactions with health care providers. Korean J Adult Nurs 2017;29:76-86.

2. Ramsey CP. Young Adult African American family members' perceptions, knowledge, attitudes, and utilization toward advance directives. ABNF J 2013;24:51-9.

3. Korea Ministry of Health and Welfare. Information on the life-sustaining treatment system: for institutions [Internet]. Sejong: Ministry of Health and Welfare; 2019 [updated 2019 June 1; cited 2019 Feb 10] . Available from: https://www.kaim.or.kr/files/ethics/\%EC\%97\%B0\%E B\%AA\%85\%EC\%9D\%98\%EB\%A3\%8C\%EA\%B2\%B0\%EC\%A0\%95\%EC\%A0\%9C\%EB\%8F\%84\%20\%EC\%95\%88\%EB\%82\%B4\%EC\%B1 \%85\%EC\%9E\%90(\%EC\%9D\%98\%EB\%A3\%8C\%EA\%B8\%B0\%EA\%B4\%80\%EC\%9A\%A9)2019.6.pdf.

4. Korea National Institute for Life Sustaining Treatment [Internet]. Seoul: Definition of advance directives [cited 2020 Feb 17]. Available from: https://www.lst.go.kr/comm/noticeList.do.

5. Matzo M, Hijjazi K, Outwater M. Older Oklahomans' knowledge, attitudes, and behaviors related to advance directives. J Gerontol Nurs 2008;34:21-6.

6. Statistics Korea [Internet]. Daejeon: Estimation of future population; 2020 [cited 2021 Feb 22]. Available from: http://kostat.go.kr/portal/ korea/kor_nw/1/2/6/index.board? bmode=read\&bSeq $=\& a S e q=373873 \&$ pageNo=1 \& rowNum=10\&navCount=10\&currPg $=\&$ searchlnfo $=\&$ Target=title\&sTxt=.

7. Chang CY. A study of the attitude toward withholding life-sustaining treatment and the characteristics of cancer patient family: Focusing on do-not-resuscitate [dissertation]. Bucheon: The Catholic Univ.; 2010. Korean.

8. Chang WK, Ahn KG, Kim MY, Kim YR, Han YJ. The role of a patient's family when the withdrawal of life-sustaining treatment is expected: A narrative analysis. Korean J Med Ethics 2015;18:172-89.

9. Jung KH, Oh YH, Kang EN, Kim KR, Lee YK, Oh ME, et al. Elderly Survey 2017 [Internet]. Sejong: Korea Ministry of Health and Welfare:; 2018 [updated 2019 June 6; cited 2020 Feb 20]. Available from:http://www.mohw.go.kr/react/jb/sjb030301 vw.jsp? PAR_MENU_ID=03\&MENU_ ID $=032901$ \& page=1 \&CONT_SEQ=344953.

10. Yang EY, Kim YA. Burden and quality of life in terminal cancer family caregivers in the area of Jeollanam-do. JKAIS 2015;16:3954-62.

11. Yang SJ, Hwang HY. A comparative study on the perceptions of elderly patients and their caregivers toward life-sustaining treatment. Korean J Med Ethics 2016;19:484-503.

12. Diwan VK, Sachs L, Wahlstrom R, Practice-knowledge-attitudes-practice: an explorative study of information in primary care. Soc Sci Med 1997:44:1221-8.

13. Kim JH, Correspondence between attitude and behavior: Effect of the importance of perceived behavior. Journal of Institute for Social Sciences 1997;8:109-21.

14. Hong SW, Kim SM. Knowledge regarding advance directives among community-dwelling elderly. J Korean Acad Soc Nurs Educ 2013;19:330-40.

15. Nolan MT, Bruder M. Patients' attitudes toward advance directives and end-of-life treatment decisions. Nurs Outlook 1997;45:204-8.

16. Lee HL, Park YH. Attitudes toward advance directives of older adults using senior centers. J Korean Gerontol Nurs 2014;16:160-9.

17. Borg V, Kristensen TS. Social class and self-rated health: can the gradient be explained by differences in life style or work environment? Soc Sci Med 2000;51:1019-30.

18. Borrell C, Muntaner C, Benach J, Artazcoz L. Social class and self-reported health status among men and women: what is the role of work organisation, household material standards and household labour? Soc Sci Med 2004;58:1869-87.

19. Ryu MH. Public knowledge and attitude towards advance directives and their intention towards withdrawing life-sustaining treatment [master's thesis]. Busan: Catholic Univ. of Pusan; 2020. Korean.

20. Jeong JH. Relationship between knowledge of end-of-life care, life-sustaining treatment, and advance directive, and the educational needs regarding writing advance directives among nurses in general hospitals [master's thesis]. Seoul: Sungshin Univ.; 2019.

21. Hwang HH. Perceived well dying, knowledge and attitude toward advance directives in older patients with chronic heart disease [master's thesis]. Seoul: Hanyang Univ.; 2017. Korean.

22. Lee MS, Kim YJ. Good death recognized by the elderly. Jour. of KoCon.a 2013;13:283-99.

23. Yun YH, Rhee YS, Nam SY, Chae YM, Heo DS, Lee SW, et al. Public attitudes toward dying with dignity and hospice. Palliative care. Korean J Hosp Palliat Care 2004;7:17-28.

24. Choi JH. Familism, filial piety and consciousness for supporting their parents among adolescent, middle, and old generation. Fam. Environ. Res. 1999;37:85-101.

25. Statistics Korea [Internet]. Daejeon: Estimation of future furniture; c1996 [cited 2021 Feb 26]. Available from: http://kostat.go.kr/portal/ korea/kor_nw/1/2/6/index.board? bmode=read\&bSeq=\&aSeq=377540\&pageNo=1 \& rowNum=10\&navCount=10\& currPg=\&searchInfo $=\&$ sTarget=title\&sTxt $=$

26. Statistics Korea [Internet]. Daejeon: 2019 Census Results; c1996 [cited 2021 Feb 26] . Available from: https://kostat.go.kr/portal/korea/ kor_nw/1/1/index.board? bmode=read\&aSeq $=384690 \&$ pageNo=\&rowNum=10\&amSeq $=\&$ sTarget $=\& s T x t=$.

27. Seo JH, Im JM, Choi JH, Lee NG, Baek SS. A study on the institutional system for improvement in dying journey and dying experiences 
the patients and their family [Internet]. Sejong: Korean Institute for Health and Social Affairs; c2018 [cited 2020 March 4]; Available from: https://www.kihasa.re.kr/publish/report/view? type=all\&seq=27932.

28. Choi EK, Hong JU, Kim MS, Keam Bs, Kim MS, Heo DS, et al. The decision-making process regarding life-sustaining treatment in four countries: Taiwan, Japan, the US, and the UK. Korean J Med Ethics 2017;20:131-51.

29. Korea Central Dementia Center [Internet]. Seoul: Legal guardian; 2020 [cited 2020 Jun 10]. Available from: https://www.nid.or.kr/main/ main.aspx. 